\title{
Proportional Representation and the Future of the American Party System
}

\section{Douglas J. Amy, Mount Holyoke College}

Few laws have had a more direct impact on American political parties than the requirement that elections be conducted in single-member districts, with the winner being the candidate with the plurality of the vote. This common electoral arrangement has played a significant role in determining the structure of the United States party system and in shaping the behavior of our parties. It is also an arrangement that has largely been taken for granted by most citizens and political scientists.

But that can no longer be the case. During the last few years, this standard requirement has come under increasing scrutiny and there now is growing interest in the possibility of introducing proportional representation (PR) elections in the U.S. - the electoral system used in most other Western industrialized democracies. Under PR rules, legislative candidates would not be elected in single-member districts, but in large multi-member districts in which the seats were allocated according to the proportion of the vote won by the various parties. ${ }^{1}$ This simple change in electoral rules would have profound impacts on the U.S. party system. This essay assesses the likelihood that PR elections will begin to be used in the U.S., and attempts to predict and evaluate some of the most likely effects PR would have on our party system. It is divided into four sections: (1) the growing interest in proportional representation elections in the U.S.; (2) the probable impacts of PR on the structure of the party system; (3) the likely changes in the behavior of parties and candidates; and (4) the normative issues concerning the desirability of a multi-party system.

\section{The Growing Interest in Proportional Representation}

Much of this interest in proportional representation has arisen in the context of recent voting rights controversies. Lani Guinier, in the aftermath of her failed nomination to the Justice Department's civil rights division, has been the most visible and vocal proponent of proportional representation

Douglas J. AmY is Associate Professor of Politics at Mount Holyoke College.

The American Review of Politics, Vol. 16, Winter, 1995: 371-383

@1995 The American Review of Politics 
elections as a remedy in voting rights cases (Guinier 1994). And now, in the wake of the Supreme Court's 1995 decision in Miller v. Johnson, in which the Court ruled unconstitutional districts created primarily on the basis of race, more political analysts are arguing that proportional representation elections are now the best hope for ensuring fair representation for racial and ethnic minorities. ${ }^{2}$ PR has the advantage of giving minorities a fair chance to elect their own representatives without all the drawbacks of trying to create special minority districts. The day after the Miller decision, USA Today's lead editorial endorsed proportional representation as the logical solution to voting rights problems, and described our current single-member district system "the undemocratic status quo" (USA Today 1995). That same year, Representative Cynthia McKinney introduced a bill into Congress that would allow the states to use proportional representation for the election of U.S. Representatives. One form of proportional representation, the cumulative vote, is already being used on the local level for elections in Chilton County, Alabama, Alamogordo, New Mexico, Peoria, Illinois, and in several dozen school districts in Texas.

A small grassroots movement has also grown up around the issue of proportional representation elections. This interest in PR has been fueled by the same kind of voter frustrations with American elections that underlies the term limits movement. Citizens in several U.S. cities, including Seattle, San Francisco, and Eugene, Oregon, have been organizing to switch their city council elections to PR. In 1991, a referendum on proportional representation made it onto the ballot in Cincinnati and won the support of 45 percent of the voters. In addition, there is now a national organization, the Center for Voting and Democracy in Washington, D.C., devoted to educating Americans about alternative election systems like proportional representation.

So, for the first time in many decades, the growing use of proportional representation elections in some jurisdictions in the United States is a very real possibility. Increasingly, the question is not "if" PR will be used in the U.S., but "when" and "where" and "how much." In that context, it is useful to try to think about what kinds of impacts PR will have on the U.S. party system. Clearly those effects are going to be profound and wide-ranging, and not a little bit controversial.

\section{Impacts on the Structure of the Party System}

\section{Threshold Levels and the Size of the Party System}

The most obvious and probable impact of PR on our party system is best expressed in the well-known Duverger rule: that single-member 
plurality elections encourage two-party systems, while proportional representation allows and encourages multi-party systems (Duverger 1951). But what kind of multi-party system will be likely to emerge in the U.S. under PR? We can engage in some informed speculation about this. For example, it is likely that we would see a moderate multi-party system, consisting of the two major parties along with two or three minor parties, rather than an extreme multi-party system with scores of parties, some very small. We know that the size of the party system under PR is strongly related to the threshold level of the particular PR system. The threshold level-the percentage of the votes that a candidate or party must receive to be elected-serves to regulate the size of the party system. For example, until recently Israel had one of the lowest threshold levels among Western democracies, approximately one percent of the national vote. As a result, the Knesset sometimes had over a dozen parties represented, many of them very small ones. In contrast, PR countries with a more moderate threshold of 4-5 percent usually have a more moderate party system of 3 to 6 parties.

Virtually all the proposals for proportional representation in the United States have contained high threshold levels. In the cumulative vote plans recommended by the Center for Voting and Democracy for congressional elections in Georgia and North Carolina, the threshold levels are between 20 and 25 percent in the multi-member districts. These very high thresholds would most likely result in a two or three party system. In the proposal for PR in Seattle, the threshold level would be 11 percent, which would probably allow for three to five parties. These moderate multi-party systems would permit increased diversity in representation, but discourage the emergence of small single-issue and extremist parties.

\section{Political Cleavages and Possible New Parties}

If we were to have a multi-party system, what new parties would be most likely to emerge? Again, we can engage in some informed speculation. Scholars of parties have long observed that viable parties tend to emerge around fundamental political cleavages in society-what are often called issue dimensions. ${ }^{3}$ They argue that parties tend to occupy the political ground on either side of these basic political divisions. So if we can identify these cleavages in American politics, then we would be better able to predict what kind of new parties will emerge under PR.

One of the most common issue dimensions among Western nations is based around socio-economic policy, and this division clearly exists in the U.S. It typically produces parties of the left and right who disagree over such issues as the desirability of social and economic equality and the proper 
role of government in society. Positions in this ideological division are already occupied by the Republican and Democratic parties, but this ideological cleavage could easily spawn at least one more party. As the Democrats have moved to the right and become a more centrist party, they are leaving considerable room on the political left-room that a new leftist party could exploit in a multi-party system. Such a party is not hard to imagine; it could easily resemble the Rainbow Coalition or the New Party. It would try to woo liberals, feminists, minorities, environmentalists, gays, left unionists, and the poor away from the Democratic fold with a platform that emphasized such things as progressive taxation, universal health coverage, affirmative action, campaign finance reform, economic democracy, and aggressive environmental protection.

Another common issue dimension in many countries is race and ethnicity. Traditionally, many political scientists have not rated that cleavage as deep enough in the U.S. to spawn a new party, but it is time to rethink that conclusion. Minorities find themselves under increasing political pressure these days, with judicial and legislative attacks on minority representation and affirmative action. Many minorities also see the bi-partisan efforts to crack down on criminals and welfare recipients as at least partially racially motivated. These events are likely to breed increasing political frustration and political isolation on the part of minorities. In regions with substantial numbers of black voters (say over $20 \%$ ), this frustration combined with a lack of political representation could easily lay the groundwork for the emergence of an African-American party.

Religion is another common issue dimension in many democracies. But this issue dimension has usually not been seen as a fundamentally divisive one here-as compared, for example, to Northern Ireland or Belgium. But we may need to rethink this assumption as well. Fundamental differences based on religious and moral views do exist in the U.S. and could spawn new parties under PR. In particular, fundamentalist and evangelical Christians are promoting a policy agenda on abortion, birth control, prayer in schools, censorship, and gay rights that is vigorously opposed by many other groups in our society. Under PR rules, a party of the Christian right, most likely resembling today's Christian Coalition, might split off from the Republican party and elect its own candidates. As Paul Weyrich recently reported, many in the Christian right are interested in a third-party effort, complaining that "we have to stop trying to beat our positions into stupid Republicans who don't understand what we're talking about. We should have somebody who represents our own values" (Lowry 1995).

Certainly there are other political divisions in our society, but it is not clear that they are deep enough to organize a viable party around. For 
example, would class differences be enough to fuel substantial interest in a Labor party? Some labor party advocates like Tony Mazzocchi clearly think so. But several factors mitigate against it, including declining levels of unionization and the lack of a socialist tradition in the U.S., which have been strong elements supporting the Labor parties in other Western countries.

Similarly, the chances of developing a successful feminist party in the U.S. are probably small. While clearly some political differences rooted in gender do exist in the American electorate, it is not clear that these issues have enough salience for enough voters to make such a party viable. Far more likely is a scenario where union activists and feminists find a place in the kind of new leftist party alluded to earlier.

Complicating these predictions is the fact that some minor parties that might not be viable on a national level, could have sufficient support on the local level to elect candidates. For example, in some areas of the western United States, parties like the Greens and the Libertarians will probably have enough regional strength to routinely elect candidates. In 1994 state senate elections in Arizona, for example, the Libertarian party garnered 19 percent of the vote in districts in which it fielded candidates (Winger 1995a).

Perhaps surprisingly, one of the least likely new parties is the one that some political observers think would be the most likely-a new centrist party. The success of centrist presidential candidates like John Anderson and Ross Perot give the impression that such a party would be feasible. But such a development is unlikely for several reasons. First, many of the supporters of candidates like Perot are not necessarily "centrist" at all-just antiRepublican and anti-Democrat. These alienated voters might easily feel more at home in some of the alternative parties likely to emerge under PR. Second, as PR encourages the leftist elements of the Democratic party to split off on their own, the Democrats will become a more centrist party. Once the Democrats more clearly occupy that centrist political niche, it will be more difficult for a rival centrist party to get a foothold in the party system. Any nascent centrist party will be very vulnerable to the Democrats poaching on its supporters.

\section{Multiple Parties: Likely But Not Inevitable}

While proportional representation will allow for the emergence of a multi-party system in the United States, and while this is the most likely outcome, it is by no means inevitable. It is possible, for instance, that PR might produce a two-party system in areas with few political cleavages. In 
countries that have a great deal of social and political homogeneity, such as Austria and the Republic of Ireland, PR has produced small party systems, with two or three parties. More highly divided societies, such as Italy, have found themselves with large numbers of parties. Similarly, earlier in this century, when PR was used in municipal elections in New York city, five parties were elected to the city council; while PR in the more politically homogeneous Cincinnati produced a two-party council. ${ }^{4}$

In addition, we can expect the two major parties to try to expand their appeal in order to prevent the emergence of rival minor parties. These large parties might offer a wider array of candidates on their party slates in an attempt to appeal to those voters who might be attracted to new minor parties. So, for example, the Democrats might include on their slate not only a centrist Democrat, but also a Green Democrat and an African-American Democrat. This strategy of offering increased representation under the traditional party banners to previously under-represented constituencies may in fact work in some jurisdictions. And it may be encouraged by the fact that many of the current proposals for PR in the U.S. are not party-list systems but candidate based systems where voters can vote for the individuals they prefer on a party's slate. But this strategy of trying to widen party offerings may often not be enough to prevent the emergence of viable minor parties. When environmentally oriented voters are given the choice between a real Green candidate and a pale green Democrat, they will likely choose the real one.

\section{A More Heterogeneous Party System}

Given that proportional representation will likely be adopted in a piecemeal fashion, in several different forms, and in different political regions, it is clearly difficult to arrive at reliable generalizations about its impact on the structure of our party system. However, we can confidently say that increased PR use in the U.S. will create a much more heterogeneous party system. Some regions will likely retain essentially a two-party system, while others will add several minor parties. Those parties and their number will vary according to the type of PR that is adopted (particularly the threshold level) and the local political culture. In the end, the result will be a party system that is more reflective of the political diversity present in the American political system.

\section{Effects on Party and Candidate Behavior}

Proportional representation will not only alter the structure of the American party system, it will also have dramatic impacts on the way that 
parties and candidates behave. The behavior of parties and candidates, particularly the way they campaign for political office, is greatly affected by the electoral environment. As PR changes that environment, candidates and parties will have to adopt new strategies to survive and prosper in these new conditions.

\section{More Competitive Districts}

One of these new conditions is a change in what it takes to be elected. Instead of candidates needing a majority or plurality of the vote, they will need only 10 or 20 percent of the vote to be successful. This one change has a number of important ramifications for party and candidate strategy. For example, with this lower threshold of success, all districts will become instantly competitive, with several parties having a good chance of electing candidates. No longer will we have the kind of safe districts that are so common in our two-party system. As a result, parties under PR will not tend to write off the districts in which they were a small minority, as is the case today. In the 1994 election, for example, either Republicans or Democrats refused to run a candidate in over 35 percent of the state legislative contests (Winger 1995b). Under PR, parties would have an incentive to mount campaigns in all districts. Even if a party could attract only 10 or 20 percent of the vote in a multi-member district, it would not be shut out; it could still win one seat. In addition, a shift of only 5 or 10 percent of the vote from one party to another could yield an extra seat for a party-a clear enticement to campaign vigorously in all districts. Parties tend to focus their resources where they have a chance to win, and under PR rules most parties will have a chance to win seats in most districts.

\section{More Issue Oriented Campaigns}

Under proportional representation, campaigns are also likely to become more issue oriented. We have long known that parties in European PR systems tend to give more emphasis to party platforms in their campaigns, but it is useful to consider how and why this is encouraged by PR. First, under $\mathrm{PR}$, there is less political risk involved in running an issue-oriented campaign. Under our current plurality rules, candidates must try to fashion a majority or plurality coalition to win. Taking clear stands on controversial issues such as abortion, gun control, and gay rights, risks alienating some voters and makes it more difficult to put together a large winning coalition. But under PR, candidates and parties do not need a majority or plurality to be successful. They do not need to try to please most of the people most of 
the time. Indeed, they can take issue stands that alienate 80 or 90 percent of the electorate and still win seats. This situation allows candidates and parties to be more candid and specific about their issue positions.

Also, as Richard Katz (1980, Chapter 2) has pointed out, the mere existence of multiple parties in a proportional representation system encourages those parties to be more specific about their policy stands. In a two-party system, parties need not be very precise to differentiate themselves from their opponents. The Republicans need only say that they want to balance the budget sooner than the Democrats. And the Democrats need only say that we should not be unduly harsh on welfare recipients. Such vague stands are enough to distinguish the parties from each other.

But a multi-party system presents parties with a much different environment. The Democrats and Republicans may find themselves surrounded on all sides by competing parties-flanked on both the left and the right. As Katz explains, this situation requires parties to be much more specific in order to clearly differentiate themselves from parties on either side. Democrats, for example, might have to differentiate their stand on environmental issues, not only from Republicans, but also from the Greens. They would have to explain not only why they opposed the environmental deregulation espoused by the Republicans, but also why they rejected the more radical environmental programs espoused by the Greens, and do so in specific policy terms. In a highly competitive environment, parties and candidates need a clear policy identity that distinguishes them from their surrounding competitors. Interestingly, in PR systems, parties often spend the most time differentiating themselves not from their sworn ideological enemies, but from the parties closest to themselves on the political spectrum-because these are the parties to which they are most likely to lose their supporters.

\section{Less Party Convergence}

A multi-party system will also tend to undermine the current trend for parties and campaigns to converge in the middle. Today both Democrats and Republicans tend to aim their campaigns at the same group of centrist swing voters that could spell the margin of victory in a single-member district race. So even though the parties have somewhat different ideologies, their campaigns tend to focus on the same issues (balancing the budget, welfare reform, reducing taxes) because they are wooing the same set of voters. This centrist strategy is rooted in two considerations that are reasonable in a two-party, single-member district system: (1) the large numbers of votes needed to win are most easily found in the center; and (2) each party can 
move toward the center because it can safely ignore its fringe supporters, who have no real alternatives. Thus the Democrats have been moving to the center in the hopes of gaining more votes, while assuming that their leftist supporters (feminists, liberals, minorities, etc.) will not defect to the Republicans.

However, in a multi-party PR system the political logic of drifting toward the center is undermined in several ways. First, parties do not need a majority of the vote to elect candidates and so they all do not have to appeal to the largest block of voters. In particular, many minor parties may have little interest in compromising their principles in an effort to compete for centrist voters. Second, in a multi-party system the major parties cannot always rely on their fringe supporters staying with them as they move toward the center. Under PR, for example, the Democrats might find themselves flanked on the left by a more progressive party. In this situation, a strategy of moving more toward the center would risk losing liberal Democrats to this new leftist party. Similarly, a Republican party moving toward the center could lose supporters to a Christian Coalition party. Indeed, in a multi-party system in which all major ideological positions are filled by parties, any major political shift by a party becomes more of a zero-sum game, with a good chance that the party will lose some of its voters to a rival.

\section{Normative Issues}

Besides the empirical questions of how proportional representation would effect the number of parties and their behavior, there are also normative questions about the desirability of these changes. For example, some observers would certainly lament the loss of the tendency for parties to converge in the middle of the political spectrum. Unfortunately, the normative debate surrounding PR is too extensive to discuss in detail here. However, several of the most important concerns about the desirability of PR should at least be mentioned and responded to, if only briefly.

\section{Would Governance Be More Difficult?}

One major concern about proportional representation is that a multiparty system would make governance more difficult. In particular, it is argued that a multi-party system will produce legislatures that are ruled by coalitions, and that these coalitions will be unstable and lead to weak and unproductive government. This is certainly a legitimate concern, given that the U.S. Congress is plagued by gridlock already. Perhaps we would be 
better off with our current two-party system, where one party usually wins a clear and workable majority in the legislature.

However, if we look at the extensive record of proportional representation in other Western democracies, we see that this concern about indecisive coalition government is largely unfounded. Almost all PR countries have enjoyed stable coalition governments. In Scandinavia, for instance, large enduring multi-party coalitions have been the rule, some of them lasting for decades. And these large coalitions have commonly passed legislation far more efficiently that has our Congress. After examining the record of PR legislatures in Europe, Oxford University's Vernon Bogdanor concluded: "There is no evidence whatsoever that proportional representation is likely to lead to instability" $(1984,187)$.

A few countries, notably Italy and Israel, have had trouble building effective governing coalitions. But both of these countries have used extreme forms of proportional representation. As noted earlier, Israel allows any party that gets over about one percent of the vote to win seats in their parliament. At times this low threshold has resulted in over a dozen parties in the Knesset, which has complicated the task of governing. However, most other PR countries use more moderate forms of PR that have a higher threshold and fewer parties. Germany has a five percent threshold that results in a workable legislature of three to five parties. This moderate PR is what proponents are advocating for the U.S.

\section{Will Multiple Parties Encourage Balkanization?}

Another common concern about proportional representation is that it would encourage the balkanization of American politics. Some worry that PR would allow candidates to be elected by appealing only to a narrow segment of the population, while our current system forces candidates to appeal to a broad majority of voters. Our two party system is seen as bringing people together in large umbrella parties, while PR would break people apart into small parties and lead to an increasingly fractious political system. In short, the concern is that PR could lead to what one critic called an "America of groups" (Quinn, Simon, and Sallet 1991).

This criticism of PR assumes that it discourages negotiation and compromise, and that winner-take-all elections naturally force candidates to try to mend political divisions. But neither of these assumptions hold up under scrutiny. For example, the current requirement that winning candidates appeal to a majority of voters has done little to discourage factionalism. Indeed, it has merely encouraged candidates to attack minority groups in an effort to win over the majority. For years, some Republican politicians, such 
as Senator Jesse Helms, have fanned the flames of racial animosity to appeal to the white majority. Other politicians have attacked gay rights to appeal to the straight majority, and yet others have castigated welfare recipients to win the votes of middle-class taxpayers. Candidates are hardly prevented from fomenting divisiveness by our current election system.

Furthermore, a multi-party proportional representation system can facilitate negotiation and compromise; it simply does so at a different stage in the election process. In our two-party system, the coalition-building usually takes place before and during the election, as our two large parties seek to knit together their diverse factions. Under PR, the coalition-building takes place after the election, in the legislatures, as the various parties negotiate and bargain to create a majority coalition and to pass legislation.

Interestingly, it could be argued that the political coalition-building that takes place in PR systems could make the negotiations between political factions much more genuine and productive than those that take place before elections in our two-party system. For example, a white Democratic candidate currently has little incentive to bargain seriously with African-American groups before an election. The candidate knows that these minorities have little choice but to vote Democratic, otherwise they risk throwing the election to the Republican candidate. However, on the legislative level, the political situation could be quite different. If we had a multi-party PR legislature, and the Democrats did not constitute a majority, they might need the votes of an African-American party to pass legislation. The minority party could withhold its support until it was given some real concessions. Thus, allowing political minorities to win seats in our legislatures could give them enough political leverage to ensure that authentic bargaining takes place. In this way, a multi-party PR system might actually encourage more genuine political dialogue and negotiation among competing political groups than does our current two-party system.

Ironically, while some Americans worry that PR will worsen group conflict, this system is widely regarded abroad as the best way to mitigate extreme political factionalism and to bolster political integration. Recent peace proposals for Northern Ireland have included plans for a new parliament elected by proportional representation. PR was also the system recently chosen by South Africa-another country that has been torn apart by violent political conflicts. All sides agreed that proportional representation and a multi-party system would be best for their diverse society. Former president F.W. de Klerk endorsed PR, arguing that the winner-take-all system "works well in homogeneous societies, but it is not the right system for a big country with vast regional interests and many language and culture groups." The African National Congress also rejected American-style elections, even 
though this system would have worked to their political advantage by overrepresenting their party in the assembly. They realized that this system would seriously under-represent whites and other minorities, which would only increase political conflicts in the long run.

Thus if Americans are concerned about increasing political divisiveness, they might do well to consider proportional representation as part of the solution. Conciliation is more likely when all groups are represented at the political table. As Arend Lijphart $(1991,31)$ has explained, "Divided societies, both in the West and elsewhere, need peaceful coexistence among the contending ethnic groups. This requires conciliation and compromise, goals that in turn require the greatest possible inclusion of representatives of these groups in the decision-making process. Such power sharing can be arranged much more easily in ... PR systems than in ... plurality systems."

\section{Conclusion}

An essay on this length can only begin to address the complex empirical and normative issues surrounding the emergence of proportional representation elections in the United States. Nevertheless, several conclusions seem warranted. First, we can no longer ignore the possibility of PR being used in this country. Second, we can no longer arbitrarily reject multi-party systems by merely assuming the natural superiority of our two-party system, as has been done in the past. The arguments for the advantages of a multiparty PR system are too numerous and too strong to be dismissed so easily. In short, political scientists and others interested in our party system must begin to take the option of proportional representation more seriously, and we must begin to more actively research, analyze, and discuss the possible effects of this change.

\section{NOTES}

${ }^{1}$ For a more detailed description of how proportional representation systems work and the case for using them in the United States, see Amy 1993.

${ }^{2}$ See, for example, William Raspberry 1995.

${ }^{3}$ See, for example, Lijphart 1984, especially Chapter 8, "Party Systems: The Issue Dimensions of Partisan Conflict."

${ }^{4}$ Proportional representation was used in two dozen U.S. cities during the earlier part of this century. For more on the history of PR in the U.S., see Amy 1993. 


\section{REFERENCES}

Amy, Douglas J. 1993. Real Choices/New Voices: The Case for Proportional Representation Elections in the United States. New York: Columbia University Press.

Bogdanor, Vernon. 1984. What is Proportional Representation? Oxford: Martin Robertson.

Duverger, Maurice. 1951. Les Partis Politiques. Paris: La Seuil.

Guinier, Lani. 1994. The Tyranny of the Majority: Fundamental Fairness in Representative Democracy. New York: Free Press.

Katz, Richard S. 1980. A Theory of Parties and Electoral Systems. Baltimore: The Johns Hopkins University Press.

Lijphart, Arend. 1991. Constitutional Choices for New Democracies. Journal of Democracy 2:30-39.

1984. Democracies: Patterns of Majoritarian and Consensus Government in Twenty-One Countries. New Haven: Yale University Press.

Lowry, Rich. 1995 Party Crashers. National Review (10 July):24-25.

Quinn, Jack, Donald Simon, and Jonathan B. Sallet. 1991. Redrawing Political Maps: An American of Groups? The Washington Post, 24 March, C1.

Raspberry, William. 1995. The Balkanization of America. The Washington Post, 7 July, Op-Ed page.

USA Today. 1995. A Route to Fairer Voting: Let Go of the Status Quo, USA Today, 30 June, $12 \mathrm{~A}$.

Winger, Richard. 1995a. November 1994 State Senate Vote for Third Parties. Ballot Access News 10, No. 13 (9 March):5.

Winger, Richard. 1995b. Dems, Reps Failed to Nominate in '94. Ballot Access News 11, No. 3 (1 June):5. 